\title{
Synthesis of graphitic carbon nanostructures from sawdust and their application as electrocatalyst supports
}

\author{
M. Sevilla, ${ }^{a}$ C. Sanchiss, ${ }^{b}$ T. Valdés-Solis, ${ }^{a}$ E. Morallón ${ }^{b}$ and
}

\author{
A. B. Fuertes ${ }^{*} a$
}

anstituto Nacional del Carbón (CSIC), P. O. Box 73, 33080-Oviedo, Spain

${ }^{\mathrm{b}}$ Departamento de Química Física e Instituto Universitario de Materiales. Universidad de

Alicante. Apartado 99. 03080-Alicante. Spain

* E-mail: abefu@incar.csic.es, Tlfn: +34 9851189 70, FAX: +34 985297662 


\begin{abstract}
We present a novel and facile synthetic method for fabricating graphitic carbon nanostructures (GCNs) from sawdust. This method is based on the use of catalysts (Fe or $\mathrm{Ni}$ ) that allows the direct conversion of sawdust into highly graphitized carbon material. The following procedure was used to obtain these graphitic nanoparticles: a) impregnation of the sawdust particles with iron or nickel salts, b) carbonization of the impregnated material at a temperature of 900 or $\left.1000^{\circ} \mathrm{C}, \mathrm{c}\right)$ selective removal of the non-graphitized carbon (amorphous carbon) by an oxidant $\left(\mathrm{KMnO}_{4}\right)$. The resulting carbon is made up of nanosized graphitic structures (i.e. nanocapsules, nanocoils, nanoribbons), which have a high crystallinity, as evidenced by TEM/SAED, XRD and Raman analysis. These GCNs were used as supports for platinum nanoparticles. Such prepared electrocatalysts show an electrocatalytical surface area close to $90 \mathrm{~m}^{2} \cdot \mathrm{g}^{-1} \mathrm{Pt}$ and they present very promising results for methanol electrooxidation.
\end{abstract}

Keywords: catalytic graphitization, catalyst support, platinum, methanol electrooxidation. 


\section{Introduction}

Widespread attention has been paid to the development of nanostructured carbon materials with graphitic framework structures. ${ }^{1}$ Accordingly, the synthesis and applications of nanostructured carbons such as nanotubes, ${ }^{1 \mathrm{c}-1 \mathrm{e}}$ nanofibers, ${ }^{\mathrm{e}-1 \mathrm{~g}}$ nanocapsules $^{1 \mathrm{~h}}$ or nanocoils ${ }^{1 \mathrm{i}}$ have been intensively studied. The unique properties of these carbon materials make them suitable for advanced applications, most of which are related with the storage and production of energy. ${ }^{2}$ Specifically, the use of these nanostructured carbons as catalytic supports in polymer-electrolyte membrane fuel cells has generated considerable attention because they meet the structural characteristics required for this application (i.e. a high crystallinity, a relatively large surface area and an open and accessible porosity). Thus, although carbon black is the most frequently employed electrocatalytic support, the use of graphitic carbon nanostructures (GCNs) such as nanotubes, ${ }^{3}$ nanofibers, ${ }^{4}$ nanocoils ${ }^{5}$ or nanocapsules ${ }^{6}$ has proved to be a good alternative.

The conventional synthetic methods used to produce GCNs include arc discharge, laser vaporization and plasma and thermal chemical vapour deposition (CVD). ${ }^{7}$ These methods require very high temperatures $\left(>5000^{\circ} \mathrm{C}\right)$, which makes them costly and complex in terms of scalability. For this reason, there is growing interest in developing low-cost and facile synthetic processes. A simple synthetic strategy for preparing GCNs is the carbonization of carbon precursors in the presence of certain transition metals (Fe, Co $\mathrm{Ni}, \mathrm{Mn}$, etc) that act as graphitization catalysts. ${ }^{8}$ The main advantage of catalytic graphitization is that both graphitizable and non-graphitizable carbons can be transformed into crystalline materials at moderate temperatures $\left(\leq 1000^{\circ} \mathrm{C}\right)$, whereas conventional graphitization requires the use of graphitizable precursors and very high 
temperatures $>2000^{\circ} \mathrm{C}$. Thus, when some types of polymeric carbons are impregnated with transition metal salts and heated in the absence of air at temperatures in the 800$1000^{\circ} \mathrm{C}$ range, a certain amount of graphitic carbon is formed. The metal particles catalyze the conversion of the non-organized carbon into graphitic carbon according to a dissolution-precipitation mechanism. ${ }^{8 \mathrm{~d}}$ Recently, we reported a novel route based on the combination of the template technique and catalytic graphitization. ${ }^{9}$ This synthetic method allows an accurate and independent control of the porosity and graphitic order. Until now, catalytic graphitization has been applied to synthetic polymeric carbon precursors such as vinyl polymers, ${ }^{10}$ polyfurfuryl alcohol, ${ }^{11}$ resorcinol-formaldehyde gels $^{5,6 \mathrm{~b}}$ and phenolic resins. ${ }^{9,12}$ However, other more available carbon precursors such as sugars or lignocellulosic materials could also be used for this purpose. Surprisingly, to the best of our knowledge, these materials have not been employed yet with this objective. Accordingly, in the present paper we propose a novel synthetic route towards GCNs based on the catalytic graphitization of a lignocellulosic material (sawdust). Moreover, we have investigated the application of $\mathrm{GCNs}$ as supports for $\mathrm{Pt}$ nanoparticles and their electrocatalytic performance in fuel cell processes such as methanol oxidation. The use of sawdust as raw material for the synthesis of GCNs has two important advantages; a) it is an inexpensive and abundant material and b) the synthetic procedure is short and facile because it can be carried out in only a few simple steps.

\section{Experimental}

\subsection{Synthesis of graphitic carbons}

The sawdust used in this work was a residue obtained from pine wood. As received, the residue was sieved to obtain a material with a particle size of $<1 \mathrm{~mm}$. In order to 
remove the inorganic residue, it was treated with $20 \% \mathrm{HCl}$ for one day, filtered, washed with water and then dried. Next, the sawdust particles were impregnated with a solution

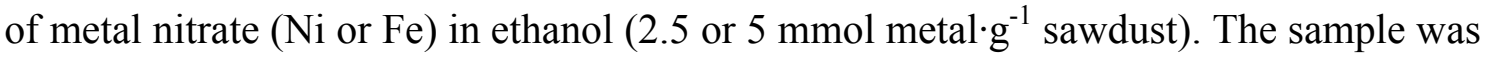
heat-treated under $\mathrm{N}_{2}$ at $900^{\circ} \mathrm{C}$ or $1000^{\circ} \mathrm{C}\left(3^{\circ} \mathrm{C} \cdot \mathrm{min}^{-1}\right)$ for $3 \mathrm{~h}$. Finally, the material was washed with $20 \% \mathrm{HCl}$ in order to remove the metal catalyst. Depending on the catalyst used ( $\mathrm{Ni}$ or $\mathrm{Fe}$ ), the carbon samples were labeled $\mathrm{CX}-\mathrm{Ni}$ and $\mathrm{CX}-\mathrm{Fe}, \mathrm{X}$ being equal to 900 or 1000 as a function of the temperature used during the heat treatment $\left(900^{\circ} \mathrm{C}\right.$ for samples impregnated with $2.5 \mathrm{mmol}$ metal $\cdot \mathrm{g}^{-1}$ sawdust or $1000^{\circ} \mathrm{C}$ for samples

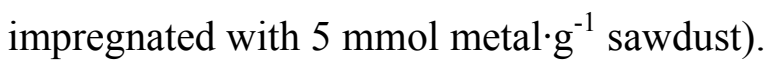

The carbon samples thus obtained consisted of a mixture of amorphous carbon and graphitic nanostructures. In order to extract pure GCNs, the catalytically graphitized carbons were oxidized (under reflux for $2 \mathrm{~h}$ ) in an acid solution of potassium permanganate with a composition (molar) of $\mathrm{H}_{2} \mathrm{O} / \mathrm{H}_{2} \mathrm{SO}_{4} / \mathrm{KMnO}_{4}=1: 0.02: 0.006$. In these experiments we employed $180 \mathrm{~mL}$ of solution per $0.8 \mathrm{~g}$ of sample. The solid products were separated by centrifugation and washed with abundant distilled water. Finally, the precipitate was treated with $10 \% \mathrm{HCl}$ to remove the $\mathrm{MnO}_{2}$. The recovered carbon samples were denoted as GCX-Ni and GCX-Fe, X being equal to 900 or 1000 .

\subsection{Preparation of Pt/GCNs electrocatalysts and electrochemical measurements.}

Platinum catalysts were synthesized as reported by Chen and Xing. ${ }^{13}$ Carbon black powder (Vulcan XC-72R, Cabot International) with a BET surface area of $270 \mathrm{~m}^{2} \cdot \mathrm{g}^{-1}$ was used as a reference support so that the performance of the prepared catalysts could be compared. The typical procedure for preparing the catalyst involves dispersing the carbon support in ethylene glycol (99.5\%, Fluka). Next, poly(vinylpyrrolidone), PVP, (Aldrich) dispersed in water is added to the ethylene glycol dispersion. ${ }^{14}$ The final ethylene glycol-water solution has a volume ratio 3:1. The amount of PVP added to the 
solution was fixed in relation to the amount of platinum, so that the mass ratio was 0.15. A predetermined amount of the Pt precursor $\mathrm{H}_{2} \mathrm{PtCl}_{6} \cdot 6 \mathrm{H}_{2} \mathrm{O}$ (ca. $40 \% \mathrm{Pt}$, Aldrich) was added to the dispersion and ultrasonicated for $10 \mathrm{~min}$. The amount of Pt precursor used was determined by the desired Pt mass loaded into the catalyst (v.g. $20 \%$ ). The Pt precursor concentration in the solution was kept constant at $0.002 \mathrm{M}$. The precursor was reduced by refluxing the polyol solution (at $\sim 140^{\circ} \mathrm{C}$ ) for $1 \mathrm{~h}$ under continuous magnetic stirring. The solution was then cooled down to room temperature, filtered and washed with acetone and ultrapure water obtained from an Elga Labwater Purelab Ultra system. The filtered solid was dried in a vacuum oven overnight. The prepared catalyst was labelled adding $\mathrm{P} t /$ to the nomenclature used for the carbon samples.

The Pt surface area (Electroactive Surface Area, ESA), was measured by cyclic voltammetry (CV) using an EG\&G Parc Mod. 175 Universal Programmer and a Potentiostat Mod. 101 HQ Instruments. A common three-electrode electrochemical cell was employed in these experiments. The electrolyte was a $0.5 \mathrm{M} \mathrm{H}_{2} \mathrm{SO}_{4}$ solution. A 0.3 $\mathrm{cm}$ diameter glassy carbon stick from Carbone Lorraine was used as working electrode and a platinum wire served as the counter electrode. All the potentials were quoted against the reversible hydrogen electrode (RHE) immersed in the same solution as that used as electrolyte. The working electrode was polished and washed ultrasonically with ultrapure water. The catalyst ink, consisting of the catalyst and a Nafion solution (5\% w/w, Aldrich) in acetone, was dropped onto the working electrode. During the experiments, nitrogen was bubbled through the solution for the purpose of deaeration for 20 minutes prior to the measurements. The CVs were recorded at a scan rate of 50 $\mathrm{mV} \cdot \mathrm{s}^{-1}$ at room temperature. Previous to this, scans at $200 \mathrm{mV} \cdot \mathrm{s}^{-1}$ up to $1.2 \mathrm{~V}$ were performed in order to clean the Pt of the catalyst layer. 
To estimate the ESA parameter from the CV plots, the following equation was employed: ESA $\left[\mathrm{cm}^{2} \cdot \mathrm{g}^{-1} \mathrm{Pt}\right]=\mathrm{Q} /\left(\mathrm{m}_{\mathrm{Pt}} \cdot \mathrm{q}_{\mathrm{H}}^{0}\right)$, where $\mathrm{Q}$ is the electrical charge $(\mathrm{mC})$ measured in the integration of the hydrogen adsorption and desorption region in the voltammogram between $0.05 \mathrm{~V}$ and $0.45 \mathrm{~V}$ after correction of the double layer charge, $\mathrm{m}_{\mathrm{Pt}}[\mathrm{g} \mathrm{Pt}]$ is the actual loading of $\mathrm{Pt}$ into the catalyst, and $\mathrm{q}_{\mathrm{H}}^{0}$ is the charge for a monolayer of one electron adsorption-desorption process on $\mathrm{Pt}$ equal to $0.210 \mathrm{mC} \cdot \mathrm{cm}^{-2} \cdot 13,15$

To evaluate the activity of the supported catalysts in relation to the methanol electrooxidation, $\mathrm{CV}$ experiments at $50 \mathrm{mV} \cdot \mathrm{s}^{-1}$ and chronoamperometric experiments were performed with a EG\&G Potentiostat Galvanostat Mod. 263A. A solution of 0.1 $\mathrm{M} \mathrm{CH}_{3} \mathrm{OH}\left(99.8 \%\right.$, Merck) in $0.5 \mathrm{M} \mathrm{H}_{2} \mathrm{SO}_{4}$ was used.

\subsection{Characterization}

Adsorption measurements of the graphitized carbons were performed using a Micromeritics ASAP 2010 volumetric adsorption system. The BET surface area was deduced from the isotherm analysis in the relative pressure range of 0.04 to 0.20 . The total pore volume was calculated from the amount adsorbed at a relative pressure of 0.99. X-ray diffraction (XRD) patterns of the GCNs were obtained on a Siemens D5000 instrument operating at $40 \mathrm{kV}$ and $20 \mathrm{~mA}$, using $\mathrm{CuK} \alpha$ radiation $(\lambda=0.15406 \mathrm{~nm}) . \mathrm{X}$ ray diffraction (XRD) patterns of the Pt catalysts were obtained on a Seifert JSODEBYEFLEX 2002 instrument, using $\mathrm{CuK} \alpha$ radiation. Transmission electron micrographs (TEM) and selected area electron diffraction (SAED) patterns of the GCNs were taken on a JEOL (JEM-2000 FX) microscope operating at $200 \mathrm{kV}$. The dispersion and size of the Pt particles were evaluated by the TEM (JEOL (JEM-2010) microscope operating at $200 \mathrm{kV}$ ). Two hundred to six hundred particles were measured for each 
sample to obtaine statistically significant results. High resolution transmission electron micrographs (HRTEM) were taken on a JEOL (JEM-3000 F) microscope operating at $300 \mathrm{kV}$. The Raman spectra were recorded with a Horiva (LabRam HR-800) spectrometer. The source of radiation was a laser operating at a wavelength of $514 \mathrm{~nm}$ and a power of $25 \mathrm{~mW}$. The loadings of Pt into the catalysts were determined by thermogravimetric analysis (TGA), which was performed in a Setaram 92-16.18 under air (Heating rate $=10^{\circ} \mathrm{C} / \mathrm{min}$ ). X-ray photoelectron spectroscopy (XPS) of the catalysts was carried out by means of a VG-Microtech Multilab spectrometer, using $\mathrm{MgK} \alpha$ $(1253.6 \mathrm{eV})$ radiation from a double anode with an energy flow of $50 \mathrm{eV}$.

\section{Results and discussion}

\section{Structural properties of graphitic carbon nanostructures (GCNs)}

When sawdust particles impregnated with a metallic salt are heat-treated under an inert atmosphere, the salt decomposes into the corresponding metallic oxides, which are subsequently reduced, as the temperature rises, by the carbon into metal nanoparticles (i.e. $\mathrm{Ni}, \mathrm{Fe}$ ). These nanoparticles have diameters in the $50-80 \mathrm{~nm}$ range as revealed by the TEM image obtained for the iron-carbon composite (Figure 1a). GCNs are formed around the metallic nanoparticles through a catalytic mechanism that involves the dissolution of amorphous carbon into catalyst particles followed by the precipitation of

graphitic carbon. ${ }^{8 \mathrm{a},}$ 8d, 11 Figure 1a shows the metallic nanoparticles surrounded by graphitic carbon shells. The thickness of the carbon layer for these nanostructures is in the 10-17 nm range, which is in good agreement with the $\mathrm{L}_{\mathrm{c}}$ values estimated from the analysis of the XRD patterns. During the thermal treatment, only the carbon in contact with the metallic nanoparticles is converted into graphitic nanostructures, the rest of the material remaining as amorphous carbon. Consequently, the carbonized material 
contains graphitic carbon nanostructures mixed with non-organized carbon. This is clearly seen in Figure $1 \mathrm{~b}$ where both types of carbon structures are displayed. The oxidation of the carbonized samples with $\mathrm{KMnO}_{4}$ allows the amorphous carbon to be removed and the graphitic carbon to be extracted. The complete elimination of amorphous carbon is verified by TEM inspection. The carbon material recovered after this oxidation step is composed of nanoparticles as evidenced by the SEM images (see insets in Figures 1c and 1d). Examination of these nanoparticles by TEM reveals that they consist of nanostructures exhibiting a large variety of morphologies. Indeed, the TEM microphotographs show the presence of nanocapsules (Figure 1c), nanocoils (Figure 1d) and nanoribbons (Figure 1e). All these nanostructures have a high crystallinity as illustrated by the SAED pattern shown in Figure 1e (Inset) and by the HRTEM image (Figure 1f) which display very well-defined (002) lattice fringes.

The XRD diffraction patterns of the GCNs synthesized at $1000^{\circ} \mathrm{C}$ (Figure 2a) confirm that these materials are well-graphitized. In fact, the samples prepared by using nickel and iron, exhibit intense XRD peaks at $2 \theta \sim 26^{\circ}, 43^{\circ}, 54^{\circ}, 78^{\circ}$ and $84^{\circ}$, which correspond to the (002), (10), (004), (110) y (112) diffractions of the graphitic framework, respectively. The structural parameters of these graphitic carbons are deduced from the analysis of the XRD spectra. Thus, the plane spacing $\left(\mathrm{d}_{002}\right)$ is calculated by applying Bragg's equation to the (002) diffraction peak, while the crystallite sizes along the c-axis, $\mathrm{L}_{\mathrm{c}}$, and a-axis, $\mathrm{L}_{\mathrm{a}}$, are deduced by means of Scherrer's equation applied to the (002) and the (110) diffraction peaks, respectively. The values of these parameters for the GCNs prepared at $900^{\circ} \mathrm{C}$ and $1000^{\circ} \mathrm{C}$ are listed in Table 1 . The $\mathrm{d}_{002}$ values for the samples synthesized with $\mathrm{Ni}$ are clearly larger $(\sim 0.34 \mathrm{~nm})$ than the graphite one $(0.3354 \mathrm{~nm})$ suggesting that the latter has turbostratic stacking. ${ }^{16}$ In contrast, the materials obtained by using iron as catalyst exhibit a high degree of 
structural order $\left(\mathrm{d}_{002}=0.336 \mathrm{~nm}\right)$, similar to that of graphite. For the CG1000-Fe sample, the sizes of the crystallites along the a- and c-axis (42 and $16 \mathrm{~nm}$ respectively) are comparable to the values of some conventional graphites. ${ }^{17}$ The SAED pattern (Figure 1e, inset) obtained for the GC1000-Fe sample evidences the high crystallinity of this material. Thus, the SAED pattern exhibits, in addition to a well-defined (002) reflection, the (100)/(101), (004), (110) and (112) rings characteristic of polycrystalline materials with a high structural organization. The presence of the (112) reflection proves the existence of the A-B sheet packing characteristic of a graphite triperiodic order. ${ }^{18}$

The Raman spectra for the graphitic carbon nanostructures obtained at $1000^{\circ} \mathrm{C}$ are displayed in Figure 2b. By means of the Raman spectroscopy it is possible to analyze the degree of structural organization of these samples. The first-order Raman spectrum (1200-1700 $\mathrm{cm}^{-1}$ ) exhibits a high-intensity sharp band at $\sim 1575 \mathrm{~cm}^{-1}$ (G band) which is associated to the $\mathrm{E}_{2 \mathrm{~g} 2}$ vibrational mode of $\mathrm{sp}^{2}$ bonded carbon atoms (Graphene sheets) and an additional weak band at $\sim 1350 \mathrm{~cm}^{-1}$ ( $\mathrm{D}$ band) which is related to the imperfections in the graphitic $\mathrm{sp}^{2}$ carbon structures. ${ }^{19}$ The $\mathrm{G}$ band has a shoulder at $1620 \mathrm{~cm}^{-1}$, known as the D' band, caused by the presence of amorphous carbon. The relative intensity ratio between the $\mathrm{D}$ and $\mathrm{G}$ bands $\left(\mathrm{I}_{\mathrm{D}} / \mathrm{I}_{\mathrm{G}}\right)$ and the width at the halfmaximum of the $\mathrm{G}$ band $\left(\Delta v_{\mathrm{G}}\right)$ reflect the degree of graphitization. Indeed, the low values for the $\left(\mathrm{I}_{\mathrm{D}} / \mathrm{I}_{\mathrm{G}}\right)$ and $\Delta v_{\mathrm{G}}$ parameters indicate a high degree of graphitization. ${ }^{20}$ These parameters are listed in Table 1. The low values obtained for the relative intensity of the two peaks $\left(\mathrm{I}_{\mathrm{D}} / \mathrm{I}_{\mathrm{G}}\right)$ and for the $\Delta v_{\mathrm{G}}$ parameter clearly point to a high degree of graphitization. In particular, the samples obtained with iron exhibit, in relation to those prepared with $\mathrm{Ni}$, lower values for the Raman parameters, which is coherent with the XRD measurements and confirms that the iron-based materials exhibit a higher 
crystallinity than nickel-based samples. In short, iron is a more effective catalyst for graphitization than nickel.

The $\mathrm{N}_{2}$ sorption isotherms for the iron catalyzed samples before $(\mathrm{C} 1000-\mathrm{Fe})$ and after (GC1000-Fe) the removal of the amorphous carbon are shown in Figure 3. The C1000-Fe sample exhibits a type IV isotherm with a H2 hysteresis loop, which is indicative of constrictions probably associated with disordered carbon. The $\mathrm{N}_{2}$ sorption isotherms obtained for the $\mathrm{C} 1000-\mathrm{Ni}, \mathrm{C} 900-\mathrm{Fe}$ and $\mathrm{C}-900-\mathrm{Ni}$ samples display a similar shape (data not shown). In contrast, for the GCNs, the $\mathrm{N}_{2}$ sorption isotherms do not contain a hysteresis loop and they exhibit high nitrogen adsorption uptakes for relative pressures $>0.9$. A representative example, is provided in Figure 3 which shows the $\mathrm{N}_{2}$ sorption isotherm obtained for the GC1000-Fe sample. The shape of this isotherm is typical of nanosized materials that do not contain framework-confined pores. In this case, the adsorption occurs at the outer surface of the nanoparticles and the estimated BET surface areas match the external surface area. This was confirmed by the results obtained from the $\alpha$-plot analysis of the $\mathrm{N}_{2}$ adsorption branch. According to these results the surface area of these materials is easily accessible, which is important for their application as electrocatalytic supports. The textural properties for the GCNs are listed in Table 1. The data shown in Table 1 reveal that the specific surface area of the GCNs diminishes as their crystallinity increases.

\section{Characterization of the Pt/GCNs}

The TEM images obtained for the Pt nanoparticles supported on the GCNs clearly show that the catalyst nanoparticles are highly dispersed over the GCNs (Figure 4). The size histograms of the deposited Pt nanoparticles (Figure 4, Insets) which were obtained by analyzing the TEM images reveal a narrow size distribution, the mean $\mathrm{Pt}$ size ranging between 2.6-2.9 $\mathrm{nm}$ (see Table 2). The high dispersion of Pt nanoparticles over 
the GCN supports is a consequence of the fact that PVP provides steric hindrance and therefore achieves results similar to those of surfactants in preventing nanoparticle aggregation. $^{21,}{ }^{22}$ These results show that the amount of PVP used is enough to prevent particle agglomeration and to ensure a uniform covering of the carbon support.

The crystalline structure of the Pt nanoparticles deposited over the GCNs was examined by means of X-ray diffraction analysis (Figure 5). The peak at $2 \theta \sim 26^{\circ}$ is associated to the (002) diffraction of GCNs (see Figure $2 b$ ) and the peaks at $2 \theta=39.7^{\circ}$, $46.3^{\circ}, 67.4^{\circ}$ and $81.2^{\circ}$ can be assigned respectively to the (111), (200), (220) and (311) planes of the face-centered cubic (fcc) structure of the Pt. ${ }^{23}$ The Pt crystallite size was deduced by means of Scherrer's equation applied to the (111) diffraction peak, leading to values similar to those obtained from TEM analysis (Table 2).

The amount of platinum in the $\mathrm{Pt} / \mathrm{GCNs}$ catalysts was estimated by means of the thermogravimetric analysis. The amount of Pt in these samples is around $20 \% \mathrm{wt}$ (see Table 2), in agreement with the theoretical amount employed in the preparation of the samples. The weight loss curves obtained for Pt/CG1000-Fe and Pt/Vulcan are represented in Figure 6. It can be seen that the oxidation temperature for the $\mathrm{Pt} / \mathrm{CG} 1000-\mathrm{Fe}$ sample is significantly higher $\left(\sim 100^{\circ} \mathrm{C}\right)$ than that of the Pt/Vulcan sample, due to the higher crystallinity of the GCNs compared to the carbon black. This result proves that the GCN supports have better stability against oxidation than carbon black, an important finding considering that carbon corrosion under an oxidative environment will lead to a considerable reduction of the durability of the catalytic system.

XPS was used to examine the state of oxidation of $\mathrm{Pt}$ in the catalysts. The $\mathrm{Pt} 4 \mathrm{f}$ core level spectra of Pt/GC1000-Ni, Pt/GC1000-Fe and Pt/Vulcan are shown in Figure 7. It can be seen that the Pt $4 \mathrm{f}$ signal consists of two doublets from the spin-orbit splitting of 
the $4 \mathrm{f}_{7 / 2}$ and $4 \mathrm{f}_{5 / 2}$ states. The most intense pair of peaks $(71.2$ and $74.4 \mathrm{eV})$ is associated to metallic Pt. The second doublet (72.5 and 75.8) can be assigned to the chemical state of Pt (II) as a consequence of the surface oxidation of the surface platinum that is in contact with air. ${ }^{24}$ The slight shift of the doublets to higher binding energies than the ones expected ( 71.1 and $72.4 \mathrm{eV})$ might be due to the interaction of the Pt particles with the support ${ }^{25}$ or to the small size of the Pt particles. ${ }^{26}$ The relative heights of the doublets indicate that metallic Pt is the predominant species.

\section{Electrocatalytic activity of Pt/GCNs}

Figure 8 shows the stabilized voltammograms obtained for the Pt/GC900-Ni, $\mathrm{Pt} / \mathrm{GC} 1000-\mathrm{Fe}$ and $\mathrm{Pt} / \mathrm{Vulcan}$ catalysts at a scan rate of $50 \mathrm{mV} \cdot \mathrm{s}^{-1}$ in $0.5 \mathrm{M} \mathrm{H}_{2} \mathrm{SO}_{4}$. The voltammetric profile is typical of a polycrystalline Pt with well defined hydrogen adsorption and desorption peaks over the different faces of the $\mathrm{Pt}$ in the potential range of 0.06-0.4 V vs. RHE. These voltammograms were used to estimate the electroactive surface area of Pt (ESA) as described in the experimental section. The ESA values deduced for the different catalysts are summarized in Table 2. The Pt/GCNs catalysts possess large values, which are in general higher than that measured for the sample used as reference (Pt/Vulcan). These results show that the metal nanoparticles are widely dispersed (see Figure 4) and that they exhibit high catalytic activity, confirming the usefulness of GCNs as electrocatalytic supports. In fact, the Pt/GCNs samples have higher ESA values than those normally reported for the electrocatalysts found in the literature, ${ }^{27}$ including the commercial catalysts such as the HiSpec9100 catalyst (Johnson Matthey), which has an ESA $=42.3 \mathrm{~m}^{2} \cdot \mathrm{g}^{-1} \mathrm{Pt}^{27 \mathrm{f}}$ However, the $\mathrm{Pt} / \mathrm{GC} 1000-\mathrm{Fe}$ shows a lower electroactive surface area of platinum than the other prepared electrocatalysts. This could be a consequence of a higher platinum nanoparticle size in this electrocatalyst in relation to the other samples (see Table 2). Thus, the histogram in 
Figure $4 d$ (inset) shows a small shift of the distribution to higher particle sizes compared to the other samples. From TEM inspection it was observed that for this sample the Pt nanoparticles form aggregates, which may cause a decrease in the platinum electroactive surface area. The carbon support in this catalyst has the highest structural order, so it has fewer defects and edge sites to which nanoparticles may be attached. It possesses also the lowest BET surface area. Both of these factors may lead to an increase in the agglomeration of platinum nanoparticles.

The catalytic activity of the prepared electrocatalysts towards methanol electrooxidation was also analyzed. Figure 9a shows the cyclic voltammograms for the Pt/GC900-Ni, Pt/GC1000-Fe and Pt/Vulcan electrocatalysts in a $0.1 \mathrm{M} \mathrm{CH}_{3} \mathrm{OH}+0.5 \mathrm{M}$ $\mathrm{H}_{2} \mathrm{SO}_{4}$ solution. The maximum current for the methanol electrooxidation in the forward scan was observed at around $0.80 \mathrm{~V}$ for $\mathrm{Pt} / \mathrm{GCNs}$ and $0.77 \mathrm{~V}$ for Pt/Vulcan with the appearance of two overlapping oxidation peaks. During the reverse scan only one oxidation peak was observed for all the electrocatalysts at around $0.70 \mathrm{~V}$ for Pt/GC1000-Fe and $0.68 \mathrm{~V}$ for Pt/GC900-Ni and Pt/Vulcan. The electrocatalytic activities measured (evaluated as the current per gram of platinum at the maximum of the anodic peak in the forward scan) are comparable to others reported in the literature for Pt supported catalysts. ${ }^{28-30}$ The $\mathrm{Pt} / \mathrm{GC} 1000-\mathrm{Fe}$ electrocatalyst has the lowest electrocatalytic activity per gram of platinum, but a high electrocatalytic activity with respect to the ESA. This was confirmed by chronoamperometric experiments (Figure $9 \mathrm{~b}$ ) performed at four potential steps from $0.2 \mathrm{~V}$ to $0.60,0.70,0.80$ and $0.85 \mathrm{~V}$. Each step was then maintained for $50 \mathrm{~s}$. The potentiostatic current decreased rapidly for all the catalysts following a diffusion controlled reaction. Figure $9 \mathrm{~b}$ shows the electrocatalytic activity for three different catalysts measured at $5 \mathrm{~s}$ plotted for the different potential steps. The highest value was obtained for the Pt/GC1000Fe 
electrocatalyst as it was obtained by cyclic voltammetry. The highest current was also obtained at $0.8 \mathrm{~V}$ (Figure 9b), which agrees with the cyclic voltammetry results.

\section{Conclusions}

In summary, we have illustrated a simple synthetic method for successfully obtaining nanosized graphitic carbon having a variety of morphologies (i.e. nanocapsules, nanocoils and nanoribbons) from sawdust. The methodology employed to obtain these carbon nanoparticles is based on the carbonization $\left(\leq 1000^{\circ} \mathrm{C}\right)$ of sawdust in the presence of $\mathrm{Fe}$ or $\mathrm{Ni}$. These nanostructures exhibit a high crystallinity as evidenced by TEM/SAED, XRD and Raman spectra. We also observed that the use of iron instead of nickel as a catalyst for graphitization produces carbon materials (nanoribbons) with a higher degree of structural order.

Nanostructured graphitic carbon was used as a support in the preparation of $\mathrm{Pt}$ electrocatalysts and the electrocatalytic activity towards methanol oxidation was measured. The Pt electrocatalysts were characterized by cyclic voltammetry, XRD and TEM techniques. The electrocatalysts obtained exhibited a good distribution of $\mathrm{Pt}$ nanoparticles and nanoparticle sizes of around 2-3 $\mathrm{nm}$. The electroactive surface areas measured by cyclic voltammetry were around $90 \mathrm{~m}^{2} \cdot \mathrm{g}^{-1} \mathrm{Pt}$. These electrocatalysts were examined for their behaviour towards methanol electrooxidation. Their electrocatalytic activity being around $200 \mathrm{~A} \cdot \mathrm{g}^{-1} \mathrm{Pt}$. We observed that an increase in the structural order of the nanostructured graphitic carbon supports favors the agglomeration of platinum particles. In spite of this, these highly graphitized materials exhibit a high electrocatalytic activity towards methanol oxidation. 
Acknowledgments. The financial support for this research work provided by the Spanish MCyT (MAT2005-00262, MAT2004-01479 and FEDER) is gratefully acknowledged. MS acknowledges the assistance of the Spanish MCyT for the award of a FPU grant. 


\section{References}

(1) (a) Subramoney, S. Adv. Mater. 1998, 10, 1157-1171. (b) Xia, Y.N.; Yang P.D.; Sun, Y.G.; Wu, Y.Y.; Mayers, B.; Gates, B.; Yin, Y.D.; Kim, F.; Yan, Y.Q. Adv. Mater. 2003, 15, 353-389. (c) Iijima, S. Nature 1991, 354, 56-58, (d) Ajayan, P.M.; Zhou, O.Z. Top. Appl. Phys. 2001, 80, 391-425. (e) Serp, P.; Corrias, M.; Kalck, P. Appl. Car. A. 2003, 253, 337-358. (f) De Jong, K.P.; Geus, J.W.; Cat. Rev.-Sci Eng. 2000, 42, 481510. (g) Rodriguez, N.M. J. Mater. Res. 1993, 8, 3233-3250. (h) Xu, B.S.; Guo, J.J.; Wang, X.M.; Liu, X.G.; Ichinose, H. Carbon 2006, 44, 2631-2634. (i) Liu, Y.; Shen, Z. Carbon 2005, 43, 1557-83.

(2) (a) Arico, A.S.; Bruce, P.; Scrosati, B.; Tarascon, J.M.; Van Schalkwijk, W. Nat. Mater. 2005, 4, 366-377. (b) Frackowiak, E.; Beguin, F. Carbon 2001, 39, 937-950. (c) Zuttel, A.; Sudan, P.; Mauron, P.; Kiyobayashi, T.; Emmenegger, C.; Schlapbach, L.; Int. J Hyd. Storage 2002, 27, 203-212. (d) Strobel, R.; Garche, J.; Moseley, P.T.; Jorissen, L.; Wolf, G. J. Power Sources 2006, 159, 781-801. (e) Orimo, S.; Zuttel, A.; Schlapbach, L.; Majer, G.; Fukunaga, T.; Fujii, H. J. Alloyds Comp., 2003, 356, 716719. (f) Liu, H.; Song, C.; Zhang, J.; Wang, H.; Wilkinson, D. P.; J. Power Sourcer 2006, 155, 95-110. (g) Joo, S.H.; Choi, S.J.; Oh, I.; Kwak, J.; Liu, Z.; Terasaki, O.; Ryoo, R. Nature 2001, 412, 169-172.

(3) (a) Liu, Z.L.; Lin, X.H.; Lee, J.Y.; Zhang, W.; Han, M.; Gan, L.M. Langmuir 2002, 18, 4054-4060. (b) Li, W.Z.; Liang, C.H.; Qiu, J.S.; Zhou, W.J.; Han, H.M.; Wei, Z.B.; Sun, G.Q.; Xin, Q.Carbon 2002, 40, 791-794. (c) Raffaelle, R.P.; Landi, B.J.; Harris, J.D.; Bailey, S.G.; Hepp, A.F. Mater. Sci. Eng. B 2005, 116, 233-243.

(4) (a) Bessel, C.A.; Laubernds, K.; Rodriguez, N.M.; Baker, R.T.K. J. Phys. Chem. B 2001, 105, 1115-1118. (b) Steigerwalt, E.S.; Deluga, G.A.; Lukehart, C.M. J. Phys. Chem. B 2002, 106, 760-766. (c) Steigerwalt, E.S.; Deluga, G.A.; Cliffel, D.E.; Lukehart, C.M. J. Phys. Chem. B 2001, 105, 8097-8101. (d) Tang, H.; Chen, J.H.; Nie, L.H.; Liu, D.Y.; Deng, W.; Kuang, Y.F.; Yao, S.Z. J. Colloid Interf. Sci. 2004, 269, 2631.

(5) (a) Hyeon, T.; Han, S.; Sung, Y. E.; Park, K. W.; Kim, Y. W. Angew. Chem. Int. Ed. 2003, 42, 4352-4356, (b) Park, K. W.; Sung, Y. E.; Han, S.; Yun, Y.; Hyeon, T. J. Phys. Chem. B 2004, 108, 939-944. 
(6) (a) Chai GS, Yoon SB, Kim JH, Yu JS Chem. Commun. 2004, 23, 2766-2767. (b) Han, S.; Yun, Y. Park, K. W.; Sung, Y. E.; Hyeon, T. Adv. Mater. 2003, 15, 1922-1925. (7) (a) Tan, C.K.; Loh, K.P.; Thong, J.T.L.; Sow, C.H.; Zhang, H. Diam. Relat. Mater. 2005, 14, 902-906. (b) Guo, T.; Nikolaev, P.; Thess, A.; Colbert, D. T.; Smalley, R. E. Chem. Phys. Lett. 1995, 243, 49-54. (c) Ma, Y.; Hue, Z.; Huo, K.; Lu, Y.; Hu, Y.; Liu, Y.; Hu, J.; Chen, Y. Carbon 2005, 43, 1667-1672. (d) Endo, M.; Takeuchi, K.; Kobori, K.; Takahashi, K.; Kroto, H. W.; Sarkar, A. Carbon 1995, 33, 873-881. (e) Meyyappan, M.; Delzeit, L.; Cassell, A.; Hash, D. Plasma Sour. Sci. Technol. 2003, 12, 205-216.

(8) (a) Derbyshire, F. J.; Presland, A. E. B.; Trimm, D. L.. Carbon 1975, 13, 111-113. (b) Marsh, H.; Warburton, A.P. Pure Appl. Chem. 1970, 20, 133-142. (c) Oya, A.; Otani, S. Carbon 1979, 17, 131-137. (d) Oya, A.; Marsh, H. J. Mater. Sci. 1982, 17, 309-322.

(9) Sevilla, M.; Fuertes, A. B. Carbon 2006, 44, 468-474.

(10) Maksimova, N. I.; Krivoruchko, O. P.; Mestl, G.; Zaikovskii, V. I.; Chuvilin, A. L.; Salanov, A. N.; Burgin, E. B. J. Mol. Catal. A Chem. 2000, 158, 301-307.

(11) Marsh, H.; Crawford, D.; Taylor, D. W. Carbon 1983, 21, 81-87.

(12) Oya, A.; Yutaka, A. M.; Otani, S. Fuel 1980, 59, 595-598.

(13) Chen, M.; Xing, Y. Langmuir 2005, 21, 9334-9338.

(14) Zaragoza-Martín, F.; Sopeña-Escario, D.; Morallón, E.; Salinas-Martínez-de Lecea. C. J. Power Sources 2007, submitted.

(15) Woods, R. Electroanal. Chem. Interf. Electrochem. 1974, 49, 217-226.

(16) Inagaki M. New carbons. Control of structure and functions. Elsevier: Amsterdam, 2000 .

(17) Cuesta , A.; Dhamelincourt, P.; Laureyns, J.; Martínez-Alonso, A.; Tascón, J. M. D. J. Mater. Chem. 1998, 8 , 2875-2879.

(18) Salver-Disma, F.; Tarascon, J.-M.; Clinard, C.; Rouzaud, J.-N. Carbon 1999, 37, 1941-1959.

(19) Sadezky, A.; Muckenhuber, H.; Grothe H.; Niessner, R.; Pöschl , U. Carbon 2005, $43,1731-1742$.

(20) Lespade, P.; Marchand, A.; Couzi, M; Cruege, F. . Carbon 1984, 22, 375-385. 
(21) Lin, K.J.; Chen, L.J.; Prasad, M. P.; Cheng, C.Y.. Adv. Mater. 2004, 16, $1845-$ 1849.

(22) Chen, C.W.; Tano, D.; Akashi, M. J. Colloid Interface Sci. 2000, 225, 349-358.

(23) Fujiwara, N.; Yasuda, K.; Ioroi, T.; Siroma, Z. Electrochim. Acta 2002, 47, 40794084.

(24) (a) Zhang, X.; Chan, K-Y. Chem. Mater. 2003, 15, 451-459. (b) Onoe, T.; Iwamoto, S.; Inoue, M. Catal. Commun. 2007, 8, 701-706. (c) Prabhuram, J.; Zhao, T.S.; Liang, Z.X.; Chen, L. R. Electrochim. Acta 2007, 52, 2649-2656.

(25) (a) Wu, G.; Chen, Y.S.; Xu, B-Q. Electrochem. Commun. 2005, 7, 1237-1243. (b) Shukla, A.K.; Arico, A.S.; El-Khatib, K.M.; Kim, H.; Antonucci, P.L.; Antonucci, V. Appl. Surf. Sci. 1999, 137, 20-29.

(26) Roth, C.; Gotees, M.; Fuess, H. J. Appl. Electrochem. 2001, 31, 793-798

(27) (a) Tamizhmani, G.; Dodelet, J.P.; Guay, D. J. Electrochem. Soc. 1996, 143, 18-23. (b) Fournier, J.; Faubert, G. ; Tilquin, J. Y.; Côté, R.; Guay, D.; Dodelet, J. P. J. Electrochem. Soc. 1997, 144, 145-154. (c) Perez, J.; Gonzalez, E.R.; Ticianelli, E.A. Electrochimica Acta 1998, 44, 1329-1339. (d) Ciureanu, M.; Wang, H. J. Electrochem. Soc. 1999, 146, 4031-4040. (e) Marie, J.; Berthon-Fabry, S.; Achard, P.; Chatenet, M.; Pradourat, A.; Chainet, E. J. Non-Crystal. Sol. 2004, 350, 88-96. (f) Joo, S.H.; Pak, C.; You, D.J.; Lee, S-A; Lee, H.I.; Kim, J.M.; Chang, H.; Seung, D. Electrochim. Acta 2006, 52, 1618-1626. (g) Xu, B.; Yang, X.; Wang, X.; Guo, J.; Liu, X. J. Power Sources 2006, 162,160-164.

(28) Liu, Z.; Ling, X.Y.; Su, X.; Lee, J.Y. J. Phys. Chem. B 2004, 108, 8234-8240.

(29) Mu, Y.; Liang, H.; Hu, J.; Jiang, L.; Wan, L. J. Phys. Chem. B 2005, 109, 2221222216.

(30) Sen, F.; Gökagaç, G. J. Phys. Chem. C, 2007, 111, 1467-1473. 


\section{$\underline{\text { Legends }}$}

Figure 1. TEM images of (a) iron-carbon nanocomposite (Iron nanoparticles are the dark areas) obtained by carbonization, (b) the carbonized sample after the removal of iron nanoparticles. GCNs obtained after the removal of amorphous carbon: (c) GC1000Ni (Inset, SEM microphotograph), (d) GC900-Ni (Inset, SEM microphotograph), (e) GC1000-Fe (Inset, SAED pattern of this sample), (f) HRTEM image of GC900-Ni. SAED pattern of GC1000-Fe (Inset Figure e): 1 - (002), 2 - (100)/(101), 3 - (004), 4 (110) and $5-(112)$.

Figure 2. (a) XRD patterns and (b) Raman spectra of graphitic carbon nanostructures obtained with nickel and iron catalysts at $1000^{\circ} \mathrm{C}$.

Figure 3. Nitrogen sorption isotherms of the samples obtained at $1000^{\circ} \mathrm{C}$ by using iron as a catalyst for the graphitization, before $\left(\mathrm{C} 1000-\mathrm{Fe}, \mathrm{S}_{\mathrm{BET}}=109 \mathrm{~m}^{2} \cdot \mathrm{g}^{-1}\right)$ and after $\left(\mathrm{GC} 1000-\mathrm{Fe}, \mathrm{S}_{\mathrm{BET}}=49 \mathrm{~m}^{2} \cdot \mathrm{g}^{-1}\right)$ the oxidation step.

Figure 4. TEM images of the Pt/GCNs: (a) Pt/CG900-Ni, (b) Pt/CG1000-Ni, (c) Pt/CG900-Fe, (d) Pt/CG1000-Fe, and (e) Pt/Vulcan.

Figure 5. XRD patterns of the Pt/GCNs: (a) Pt/Vulcan, (b) Pt/CG900-Ni, (c) Pt/CG1000-Ni, (d) Pt/CG900-Fe and (e) Pt/CG1000-Fe.

Figure 6. TGA curves of the Pt/GCNs.

Figure 7. Pt $4 \mathrm{f}$ electron spectra of the $\mathrm{Pt} / \mathrm{GCNs}$.

Figure 8. Cyclic voltammograms for the Pt/GC900-Ni, Pt/GC1000-Fe and Pt/Vulcan electrodes in a $0.5 \mathrm{M} \mathrm{H}_{2} \mathrm{SO}_{4}$ solution at $50 \mathrm{mV} \cdot \mathrm{s}^{-1}$.

Figure 9. (a) Cyclic voltammograms of room-temperature methanol oxidation on the $\mathrm{Pt} / \mathrm{GC} 900-\mathrm{Ni}, \mathrm{Pt} / \mathrm{GC} 1000-\mathrm{Fe}$ and Pt/Vulcan catalysts in $0.1 \mathrm{M} \mathrm{CH}_{3} \mathrm{OH}$ in $0.5 \mathrm{M} \mathrm{H}_{2} \mathrm{SO}_{4}$ at $50 \mathrm{mV} \cdot \mathrm{s}^{-1}$, (b) I (5 s) - V curves derived from chronoamperometry experiments for the Pt/GC900-Ni, Pt/GC1000-Fe and Pt/Vulcan catalysts in a $0.1 \mathrm{M} \mathrm{CH}_{3} \mathrm{OH}+0.5 \mathrm{M}$ $\mathrm{H}_{2} \mathrm{SO}_{4}$ solution. 
Table 1. Physical properties of synthetized graphitic carbons.

\begin{tabular}{|c|c|c|c|c|c|c|c|}
\hline \multirow{2}{*}{ Sample } & \multicolumn{2}{|c|}{$\begin{array}{c}\text { Textural } \\
\text { properties }\end{array}$} & \multicolumn{3}{|c|}{$\begin{array}{c}\text { Structural } \\
\text { characteristics }\end{array}$} & \multicolumn{2}{|c|}{$\begin{array}{c}\text { Raman } \\
\text { parameters }\end{array}$} \\
\hline & $\begin{array}{c}\mathrm{S}_{\mathrm{BET}} \\
\left(\mathrm{m}^{2} \cdot \mathrm{g}^{-1}\right)\end{array}$ & $\begin{array}{c}\mathrm{V}_{\mathrm{p}} \\
\left(\mathrm{cm}^{3} \cdot \mathrm{g}^{-1}\right)\end{array}$ & $\begin{array}{l}\mathrm{d}_{002} \\
(\mathrm{~nm})\end{array}$ & $\begin{array}{c}\mathrm{L}_{\mathrm{c}} \\
(\mathrm{nm})\end{array}$ & $\begin{array}{c}\mathrm{L}_{\mathrm{a}} \\
(\mathrm{nm})\end{array}$ & $\mathrm{I}_{\mathrm{D}} / \mathrm{I}_{\mathrm{G}}$ & $\begin{array}{c}\Delta v_{\mathrm{G}} \\
\left(\mathrm{cm}^{-1}\right)\end{array}$ \\
\hline GC900-Ni & 112 & 0.58 & 0.341 & 9.8 & 25 & 0.897 & 27.9 \\
\hline GC1000-Ni & 107 & 0.52 & 0.342 & 10.0 & 28 & 0.661 & 23.4 \\
\hline GC900-Fe & 96 & 0.46 & 0.338 & 12.3 & 39 & 0.624 & 26.1 \\
\hline GC1000-Fe & 49 & 0.29 & 0.336 & 16.3 & 42 & 0.381 & 21.0 \\
\hline
\end{tabular}


Table 2. Physical properties of $\mathrm{Pt} / \mathrm{GCNs}$ electroctalysts

\begin{tabular}{|c|c|c|c|c|c|c|c|}
\hline \multirow{3}{*}{ Sample } & \multirow{3}{*}{$\begin{array}{c}\text { Pt } \\
(w t \%)\end{array}$} & \multirow{3}{*}{$\begin{array}{c}\text { EAS } \\
\left(\mathrm{m}^{2} \cdot \mathrm{g}^{-1} \mathrm{Pt}\right)\end{array}$} & \multicolumn{2}{|c|}{ Pt size (nm) } & \multicolumn{3}{|c|}{ Electrocatalytic activity } \\
\hline & & & \multirow{2}{*}{ XRD } & \multirow{2}{*}{ TEM $^{\mathrm{a}}$} & \multicolumn{2}{|c|}{$\mathbf{I}_{\mathrm{f}}($ voltam. exp) } & \multirow{2}{*}{$\begin{array}{c}I^{\mathrm{b}}(\text { chronoamp. exp }) \\
\left(\mathrm{A} \cdot \mathrm{g}^{-1} \mathrm{Pt}\right)\end{array}$} \\
\hline & & & & & $\left(\mathrm{A} \cdot \mathrm{g}^{-1} \mathrm{Pt}\right)$ & $\left(\mu \mathrm{A} \cdot \mathrm{cm}^{2}{ }^{2} \mathrm{ESA}\right)$ & \\
\hline GC900-Fe & 19.3 & 88.9 & 2.3 & $2.7(0.4)$ & 209 & 235 & -- \\
\hline GC1000-Fe & 20.8 & 65.6 & 2.7 & $2.9(0.5)$ & 167 & 254 & 101 \\
\hline GC900-Ni & 20.0 & 93.4 & 2.5 & $2.6(0.5)$ & 182 & 195 & 83 \\
\hline GC1000-Ni & 19.9 & 80.2 & 2.7 & $2.7(0.5)$ & 220 & 273 & -- \\
\hline Pt/Vulcan & 20.9 & 73.6 & 2.2 & $2.6(0.5)$ & 200 & 272 & 93 \\
\hline
\end{tabular}

${ }^{a}$ Mean Pt size. In parenthesis are indicated the standard deviations

${ }^{\mathrm{b}}$ This measurement was obtained after $5 \mathrm{~s}$ at $0.8 \mathrm{~V}$. 

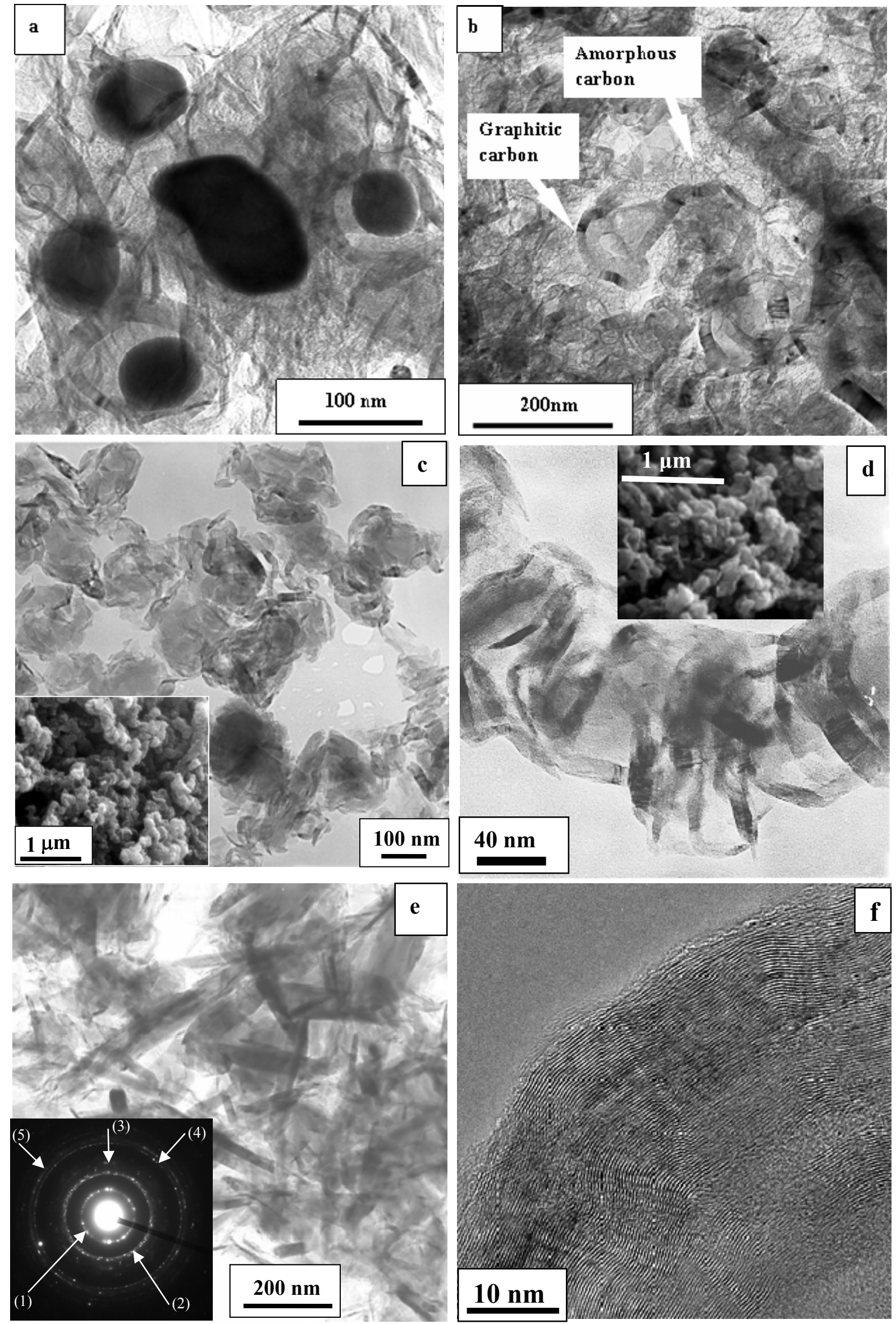

Figure 1 

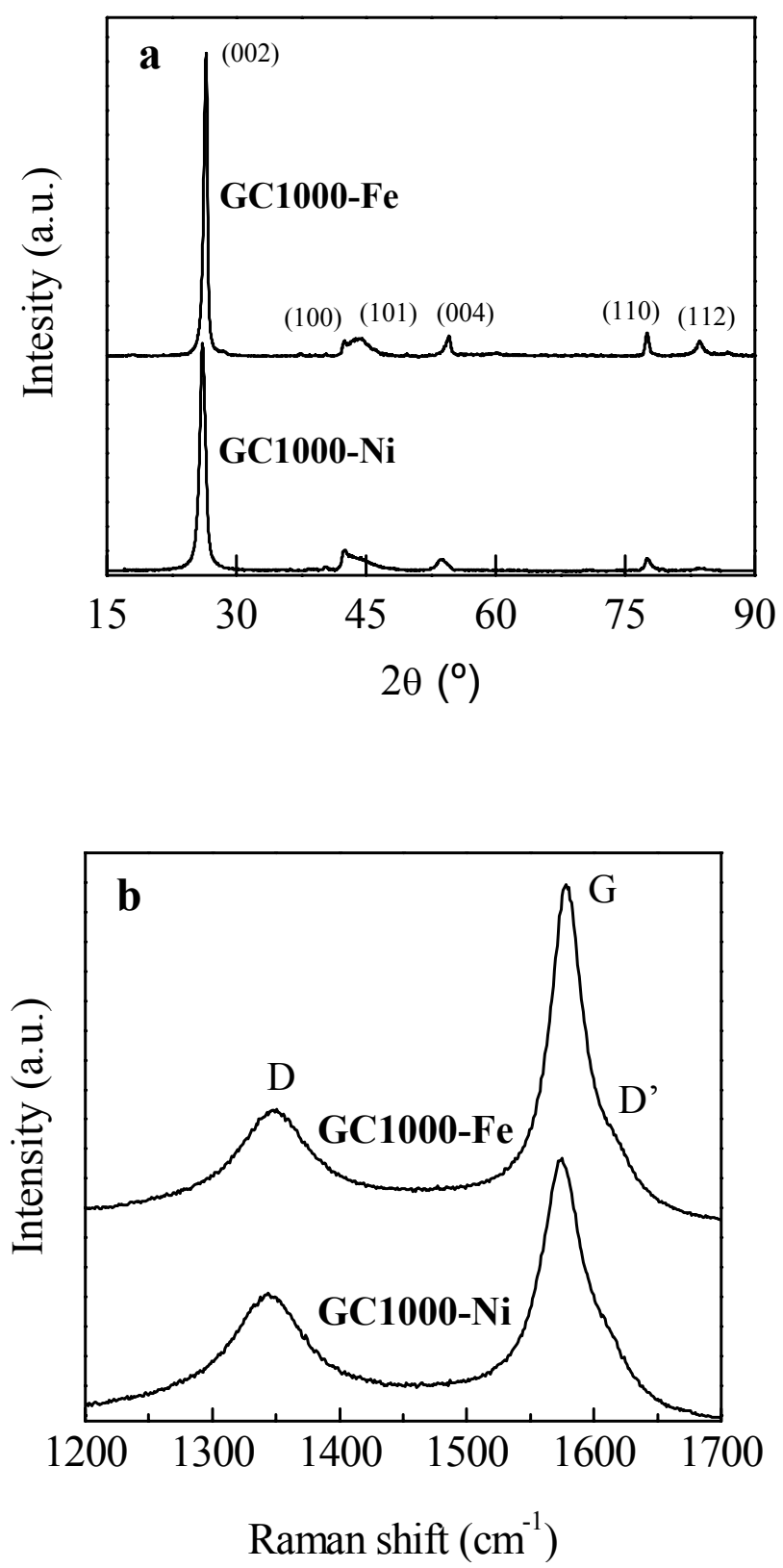

Figure 2 


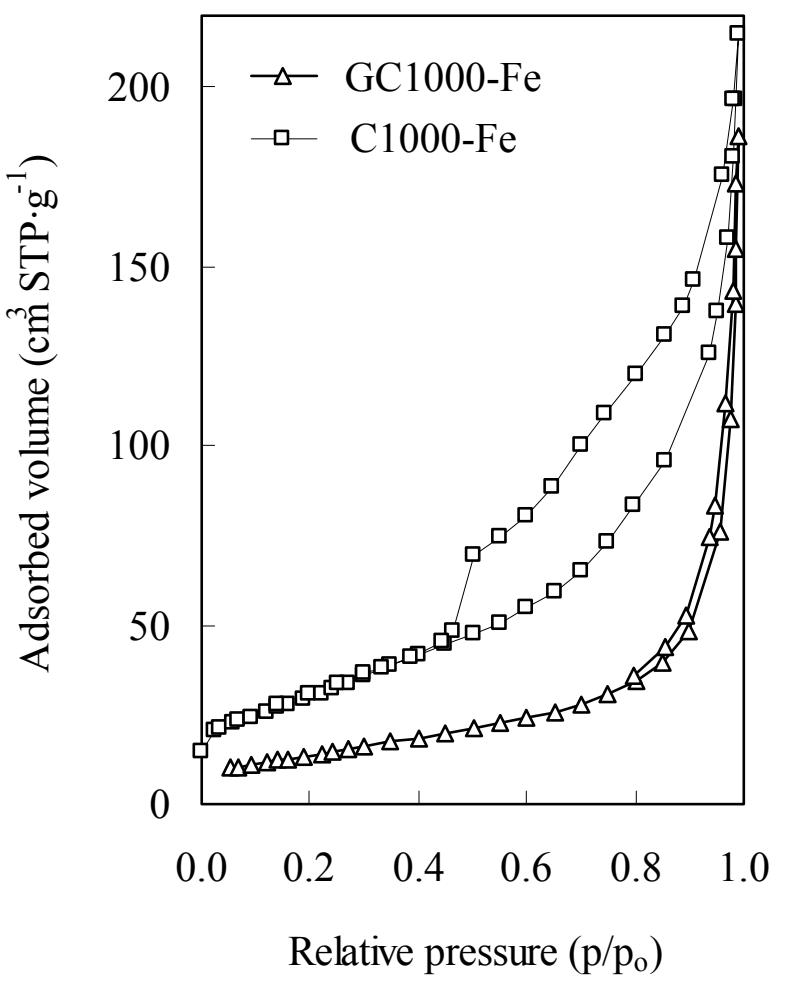

Figure 3 

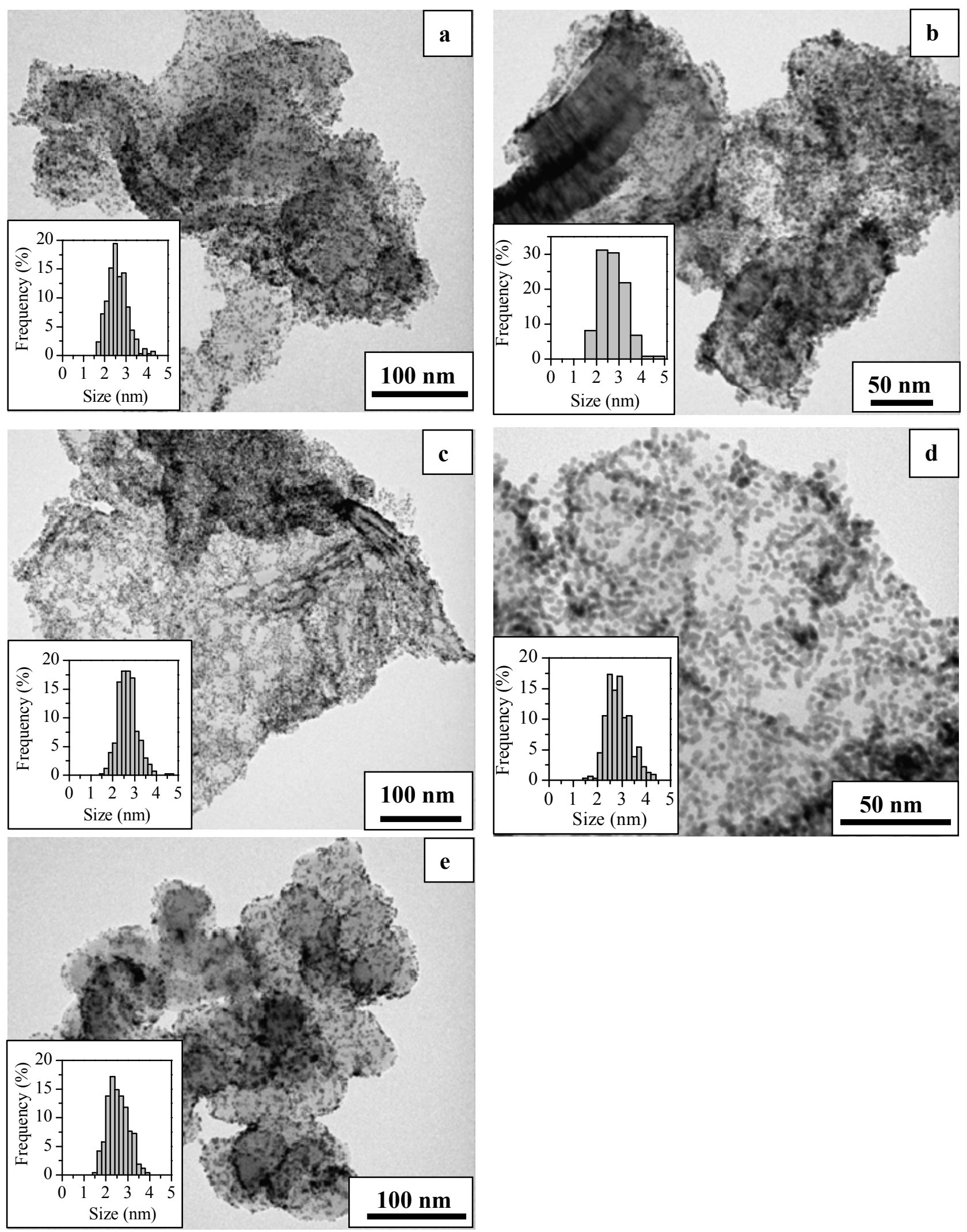

Figure 4 


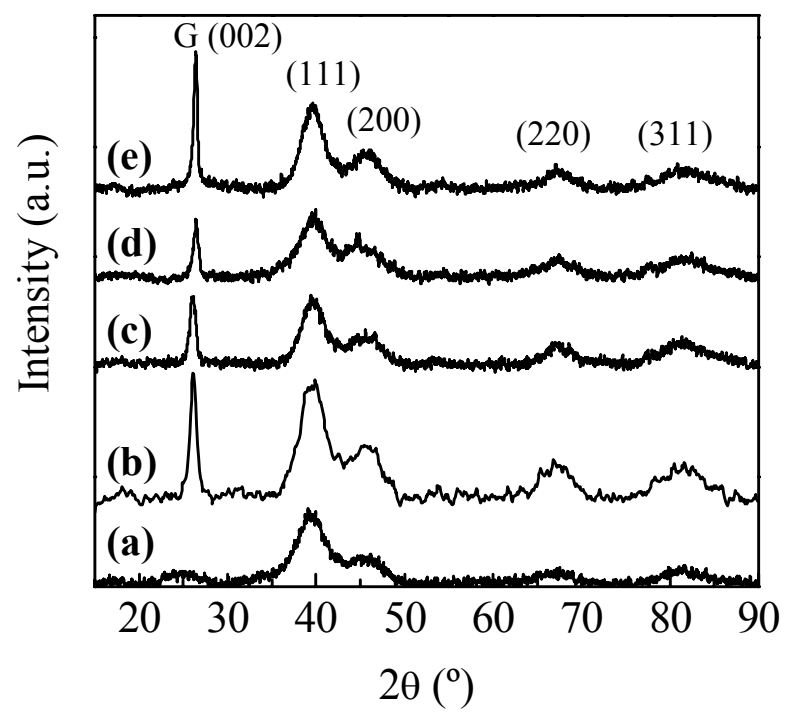

Figure 5 


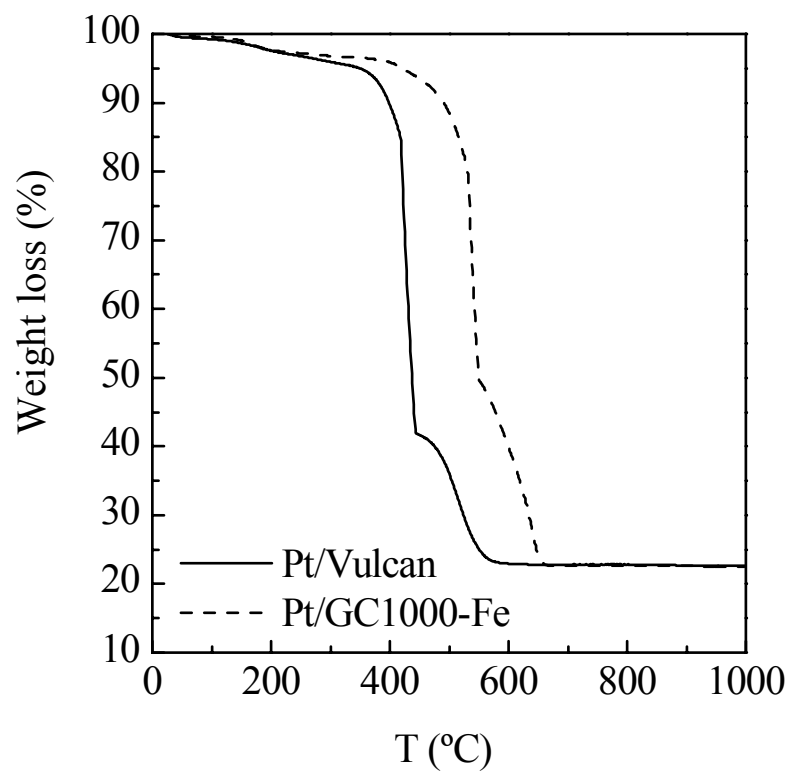

Figure 6 

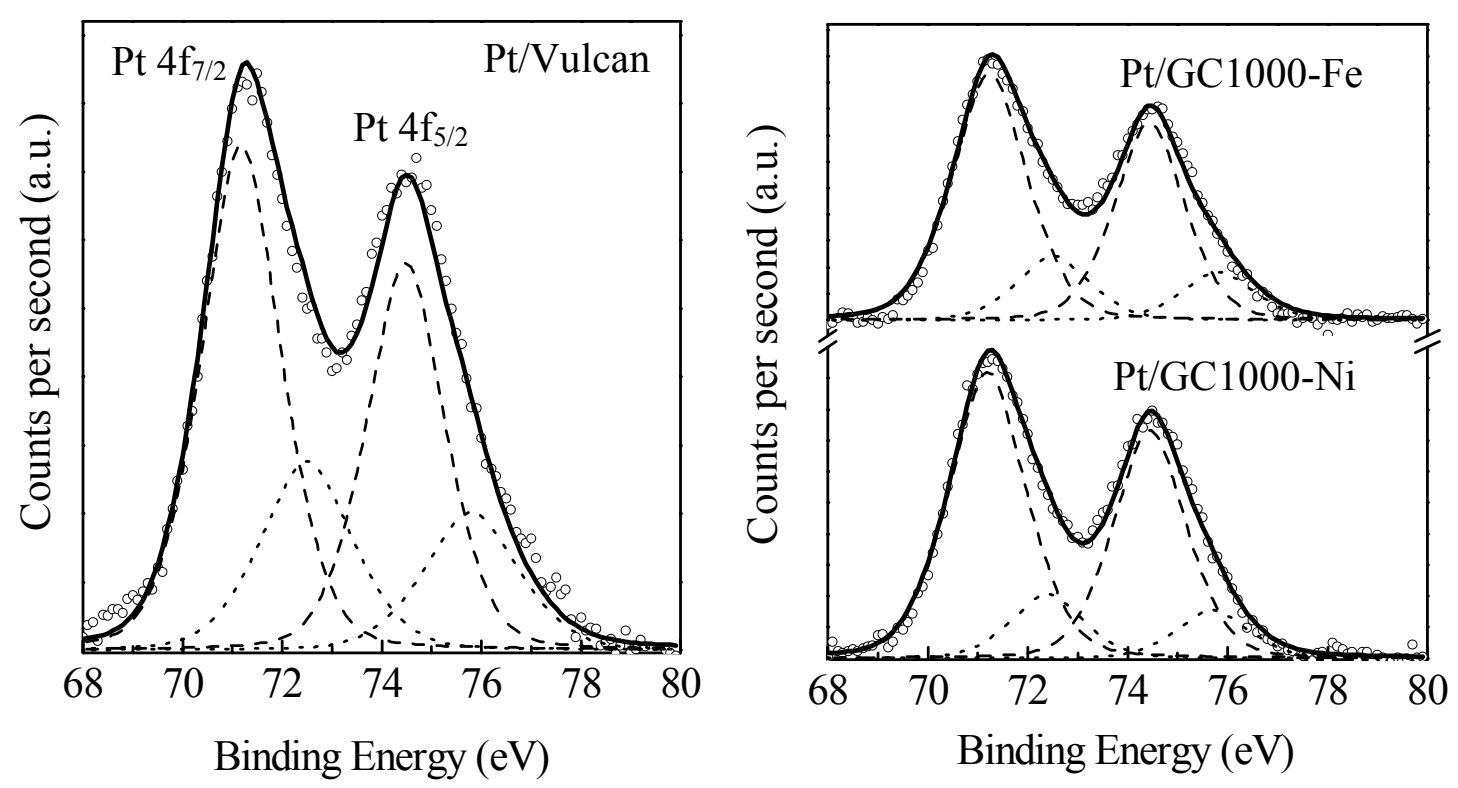

Figure 7 


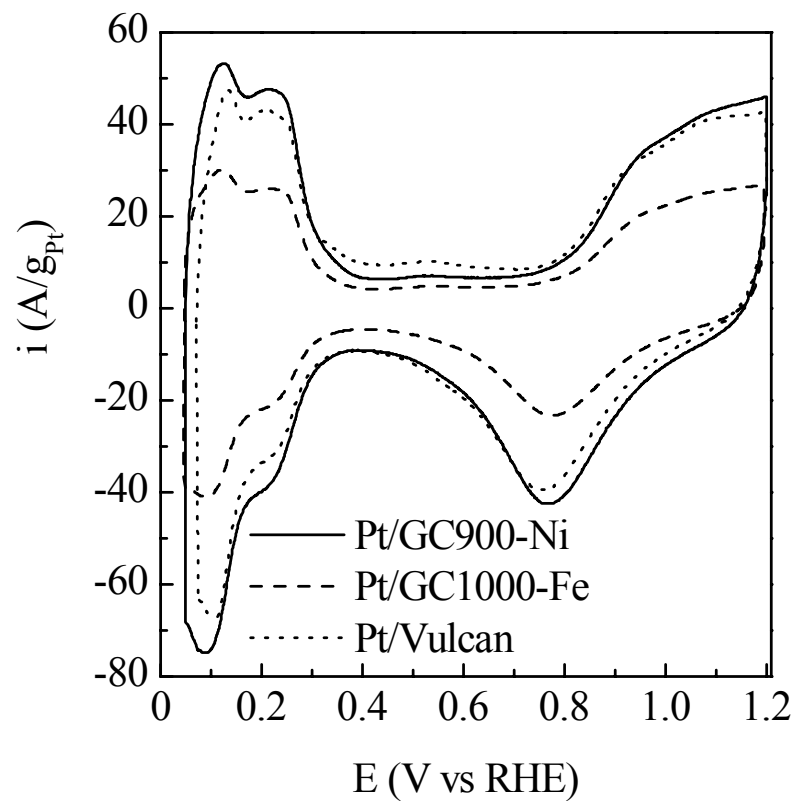

Figure 8 

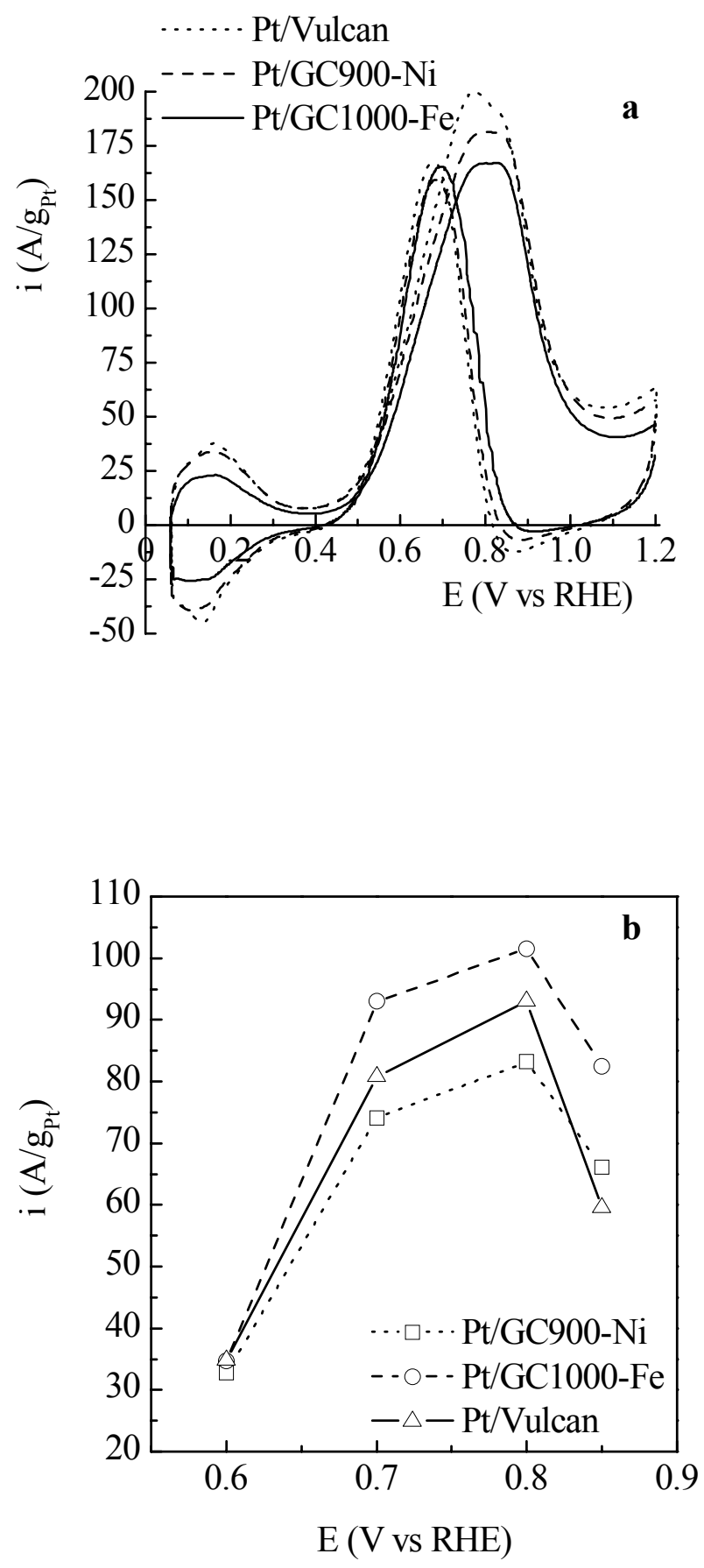

Figure 9 